\title{
Tetraethyl Orthosilicate Coated Hydroxyapatite Powders for Lead Ions Removal from Aqueous Solutions
}

\author{
Rodica V. Ghita, ${ }^{1}$ Simona Liliana Iconaru, ${ }^{1,2}$ Cristina Liana Popa, ${ }^{1,3}$ Adrian Costescu, ${ }^{4}$ \\ Philippe Le Coustumer, ${ }^{5}$ Mikael Motelica-Heino, ${ }^{2}$ and Carmen Steluta Ciobanu ${ }^{1}$ \\ ${ }^{1}$ National Institute of Materials Physics, P.O. Box MG 07, 077125 Magurele, Romania \\ ${ }^{2}$ ISTO, UMR 7327 CNRS-Université d'Orléans, 1 A rue de la Férollerie, 45071 Orléans Cedex 2, France \\ ${ }^{3}$ Faculty of Physics, University of Bucharest, 405 Atomistilor, P.O. Box MG-1, 077125 Magurele, Romania \\ ${ }^{4}$ Hyperion University of Bucharest, 169 Calea Călăraşilor, 030615 Bucharest, Romania \\ ${ }^{5}$ Universite Bordeaux, EA 4592 Géoressources \& Environnement, ENSEGID, 1 allée F. Daguin, 33607 Pessac Cedex, France
}

Correspondence should be addressed to Carmen Steluta Ciobanu; ciobanucs@gmail.com

Received 21 June 2014; Accepted 8 July 2014; Published 21 July 2014

Academic Editor: Daniela Predoi

Copyright (C) 2014 Rodica V. Ghita et al. This is an open access article distributed under the Creative Commons Attribution License, which permits unrestricted use, distribution, and reproduction in any medium, provided the original work is properly cited.

\begin{abstract}
The goal of this study was to synthetize and characterize a porous material based on tetraethyl orthosilicate (TEOS) coated hydroxyapatite (HApTh) after removal experiments of $\mathrm{Pb}^{2+}$ ions from aqueous solutions. In order to study the morphology and composition, the samples obtained after removal experiments of $\mathrm{Pb}^{2+}$ ions from aqueous solution with the initial $\mathrm{Pb}^{2+}$ ion concentrations of the aqueous solutions were $0.1 \mathrm{~g} \cdot \mathrm{L}^{-1}$ (HApTh-50) and $0.9 \mathrm{~g} \cdot \mathrm{L}^{-1}$ (HApTh-450) have been investigated by scanning electron microscopy (SEM) equipped with an energy dispersive X-ray spectrometer (EDS), Fourier transform infrared spectroscopy (FTIR), and transmission electron microscopy (TEM). Removal experiments of $\mathrm{Pb}^{2+}$ ions were carried out in aqueous solutions with controlled concentration of $\mathrm{Pb}^{2+}$. After the removal experiment of $\mathrm{Pb}^{2+}$ ions from solutions, porous hydroxyapatite nanoparticles were transformed into HApTh-50 and HApTh- 450 due to the adsorption of $\mathrm{Pb}^{2+}$ ions followed by a cation exchange reaction. The obtained results show that the porous $\mathrm{HApTh}$ nanopowders could be used for $\mathrm{Pb}^{2+}$ ions removal from aqueous solutions.
\end{abstract}

\section{Introduction}

One of the major problems encountered in the public health area worldwide is the poisoning with various heavy metals. Researchers around the world have turned their attention to finding new effective and cost-efficient methods for depollution, considering the fact that heavy metals are nonbiodegradable, having the tendency to accumulate in living bodies, leading to disorders of different functions and to serious diseases $[1,2]$. Lead $(\mathrm{Pb})$ is a very toxic heavy metal, found in the earth's crust with an average concentration of $16 \mathrm{mg} / \mathrm{kg}$ in soils $[3,4]$. On the other hand, lead has been extensively used in various industries, being a constituent in building materials, pipes, lead-acid batteries, bullets, and paints. In a report released by the Agency for Toxic Substances and Disease Registry (ATSDR), in 2007, the harmful effect of lead on the human nervous and reproductive systems was emphasized. Contamination of wastewaters represents a major concern because this is one way of lead bioaccumulation in the food chain [3]. Recent studies have revealed that children are more susceptible to lead poisoning, their bodies being able to absorb around $50 \%$ of inhaled or ingested lead and the effects being more pronounced and long-lasting, compared to adults [5]. Moreover, the effects of chronic lead exposure to various functions of the human body have already been reported $[3,6]$. In this context, many researchers have focused their attention to developing different methods for dangerous heavy metals removal from wastewaters. Among the methods already used, chemical precipitation, membrane filtration, ion-exchange, and adsorption could be mentioned [7-9]. Of all these methods, the most preferred one is the adsorption of heavy metals ions from aqueous solution using cost-efficient materials [7-9]. Previous studies have revealed that apatites are able to successfully remove lead from aqueous solutions $[4,10]$. The best known member of the apatite family is hydroxyapatite (HAp). Synthetic hydroxyapatite, 
$\mathrm{Ca}_{10}\left(\mathrm{PO}_{4}\right)_{6}(\mathrm{OH})_{2}$, has been used in the last decades in many biomedical applications as coating for orthopedic or dental implants or as filling material for various injuries or defects, being similar to the natural mineral component of the human bones and teeth [11]. Furthermore, two of the most appealing properties for environmental applications that HAp possesses are its ability to adsorb complex organic materials and the capacity of heavy metals ion-exchanging [11-14]. Previous studies have shown that $\mathrm{Pb}^{2+}$ ions exchange rapidly with $\mathrm{Ca}$, this process inducing morphological changes in the surface region [15-17]. In order to increase the adsorption ability of hydroxyapatite, an increase in its porosity must be obtained. Therefore, doping hydroxyapatite with silicon ions may be the key to increase the porosity, thus creating a better material for lead removal from aqueous solutions. Recent studies have shown that the addition of tetraethoxysilane (TEOS) can induce the formation of large textural pores [18]. Consequently, in order to increase the lead adsorption capacity of hydroxyapatite, it must be doped with a silicon based compound, such as TEOS.

The goal of this study was to synthetize and characterize new porous material based on tetraethyl orthosilicate (TEOS) and hydroxyapatite (HApTh) after removal experiment of $\mathrm{Pb}^{2+}$ ions from aqueous solution. The obtained powders after removal experiment of $\mathrm{Pb}^{2+}$ ions from aqueous solution when the initial $\mathrm{Pb}^{2+}$ ion concentrations of the aqueous solutions were $0.1 \mathrm{~g} \cdot \mathrm{L}^{-1}$ (HApTh-50) and $0.9 \mathrm{~g} \cdot \mathrm{L}^{-1}$ (HApTh450 ) have been investigated by scanning electron microscopy (SEM), transmission electron microscopy (TEM), and Fourier transform infrared spectroscopy (FTIR). Another objective was to investigate the removal of $\mathrm{Pb}^{2+}$ ions from aqueous solutions with different $\mathrm{pH}$ values using HApTh nanopowders.

\section{Experimental Section}

2.1. Materials. All the reagents including ammonium dihydrogen phosphate $\left[\left(\mathrm{NH}_{4}\right)_{2} \mathrm{HPO}_{4}\right]$ (Alpha Aesar), calcium nitrate tetrahydrate $\left[\mathrm{Ca}\left(\mathrm{NO}_{3}\right)_{2} \cdot 4 \mathrm{H}_{2} \mathrm{O}\right]$ (Alpha Aesar), ethanol, and tetraethyl orthosilicate (TEOS) with $99.999 \%$ purity were purchased from Sigma-Aldrich and lead nitrate $\left[\mathrm{Pb}\left(\mathrm{NO}_{3}\right)_{2}\right]$ with $99.5 \%$ purity was purchased from Merck and used without further purification.

\subsection{Synthesis of Hydroxyapatite/TEOS Nanocomposites.} Hydroxyapatite/TEOS nanocomposites (HApTh) were prepared using tetraethyl orthosilicate and hydroxyapatite. The hydroxyapatite $\left(\mathrm{Ca}_{10}\left(\mathrm{PO}_{4}\right)_{6}(\mathrm{OH})_{2}\right)$ nanoparticles were prepared by setting the atomic ratio of $\mathrm{Ca} / \mathrm{P}$ at 1.67 in accord with $[19,20]$. The hydroxyapatite (HAp) was immobilized into a tetraethyl orthosilicate foam using the technique reported in the literature [20]. HApTh was obtained when tetraethyl orthosilicate solution ( $1 \mathrm{~g} \mathrm{HAp} / 10 \mathrm{~mL}$ ) was dropped on the HAp powder. The mixtures were then stirred vigorously for $30 \mathrm{~min}$ until homogeneity was achieved. After forming stable structures, HApTh composites were allowed to dry at $80^{\circ} \mathrm{C}$ for $24 \mathrm{~h}$ in a vacuum oven for the excess solvent to evaporate. Finally, HApTh composite samples were then ground in order to obtain powders.
2.3. Samples Characterization. In order to investigate the composition and morphology of the samples an equipment FESEM HITACHI 4700 coupled with an energy dispersive Xray attachment (EDAX/2001 device) was used. TEM studies were carried out using a FEI Tecnai 12 (FEI Company, Hillsboro, OR, USA) equipped with a low-dose digital camera from Gatan Inc. (Pleasanton, CA, USA). Small quantities of HApTh powder were dispersed in deionised water and deposited on a copper grid coated with carbon film. This technique allows a good definition of crystal morphology.

The FTIR spectra were acquired using a Spectrum BX spectrometer. Pellets of $10 \mathrm{~mm}$ diameter for FTIR measurements were prepared ( $1 \%$ of the powder was mixed and ground with $99 \% \mathrm{KBr}$ ) by pressing the powder mixture at a load of 5 tons for $2 \mathrm{~min}$. The spectra were registered in the range from 400 to $4000 \mathrm{~cm}^{-1}$ with a resolution of 4 and 128 times scanning.

The Raman spectra were registered with a Renishaw InVia dispersive Raman spectrometer (2012), equipped with a Leica DM microscope and one laser source at $514 \mathrm{~nm}$ (gas-type), Spectra Physics Ar ion laser $(20 \mathrm{~mW})$. The samples were analyzed using the $514 \mathrm{~nm}$ laser with a power at $0.2 \mathrm{~mW}$ and $1800 \mathrm{~L} / \mathrm{mm}$ gratings. The spectral range covered for all spectra is $100-2000 \mathrm{~cm}^{-1}$ with a resolution below $2 \mathrm{~cm}^{-1}$. Prior to each reference measurement, the instrument was calibrated on the internal Si-reference standard $\left(520.6 \pm 0.1 \mathrm{~cm}^{-1}\right)$.

The removal performance of $\mathrm{Pb}^{2+}$ ions by the HApTh powders was investigated by batch experiments, monitoring the change of $\mathrm{Pb}^{2+}$ ion concentration in the aqueous solutions. For these experiments, $5 \mathrm{~g}$ of HApTh nanocomposites were added to $500 \mathrm{~mL}$ aqueous solution with various initial $\mathrm{Pb}^{2+}$ ion concentrations and $\mathrm{pH}$ values in accord with Jang et al. [21]. The initial $\mathrm{Pb}^{2+}$ ion concentrations of the aqueous solutions were controlled and the values were set in the range $0.1-1.5 \mathrm{~g} \cdot \mathrm{L}^{-1}$ by dissolving lead nitrate $\left[\mathrm{Pb}\left(\mathrm{NO}_{3}\right)_{2}\right]$ in deionized water. The $\mathrm{pH}$ values of aqueous solutions with controlled initial $\mathrm{Pb}^{2+}$ ion concentrations were adjusted from 3 to 6 by adding small amounts of $0.1 \mathrm{M} \mathrm{HCl}$ standard solution. For all experiments the solution was stirred constantly for $24 \mathrm{~h}$ by a mechanical stirrer at room temperature.

\section{Results and Discussions}

Scanning electron microscopy (SEM) was used to characterize the morphology and elemental composition of synthesized powders after lead removal experiments. SEM images presented in Figure 1 showed that lead incorporation into HApTh samples affects the particle shape. The crystal clusters with needle or rod-like shapes were observed in SEM micrographs for the HApTh-50 and HApTh-450 samples. The clusters with needle or rod-like shapes were distinguished when the $\mathrm{Pb}^{2+}$ ion concentration from the aqueous solutions was $0.9 \mathrm{~g} \cdot \mathrm{L}^{-1}$ (HApTh-450 samples).

The EDX analysis indicates that calcium, phosphorus, silicon, and oxygen are the major constituents of the samples. The presence of $\mathrm{Pb}$ is also observed.

Figure 2 shows the TEM image of HApTh powders after the sorption experiment. These nanoparticles exhibit 


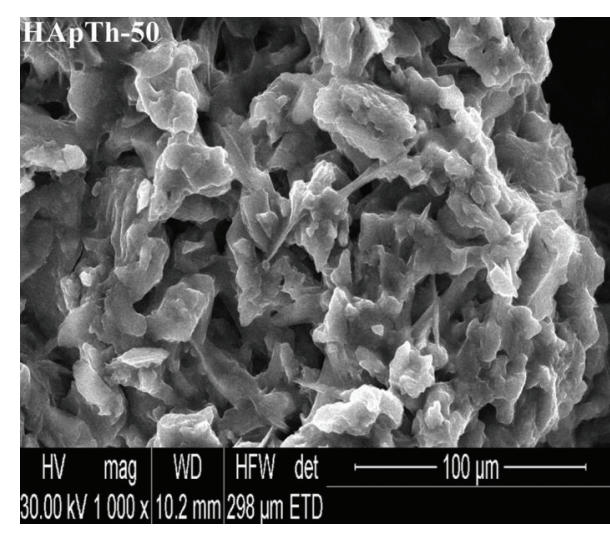

(a)

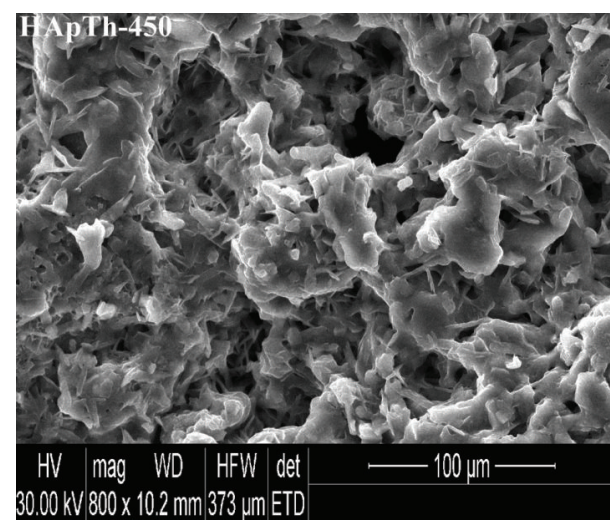

(b)

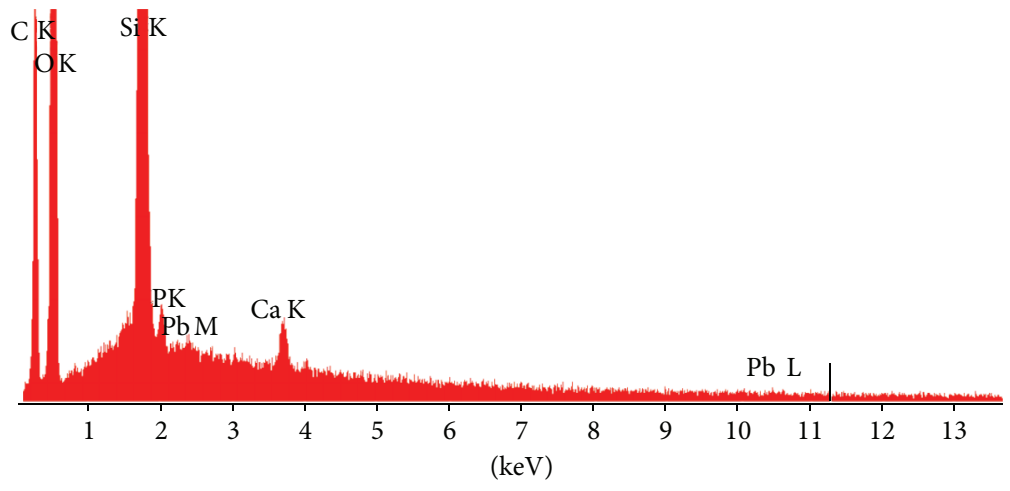

(c)

FIgURE 1: SEM micrographs with EDX spectra for the (a) HApTh-50 and (b) HApTh-450 samples.

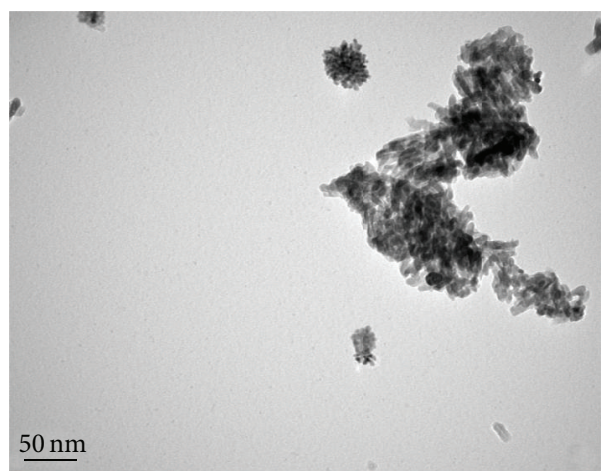

(a)

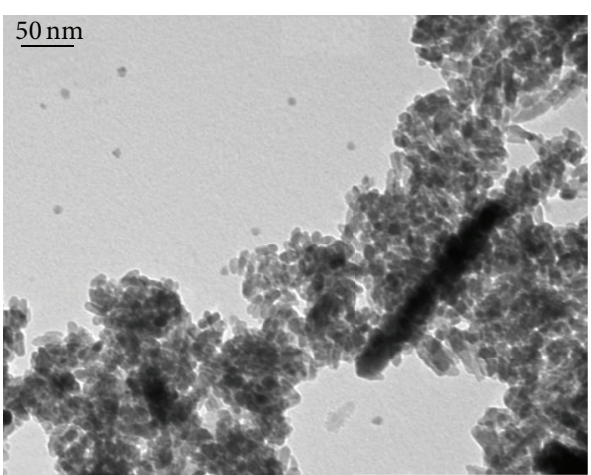

(b)

FIgURE 2: TEM micrograph of HAp after $\mathrm{Pb}^{2+}$ removal experiments for: (a) HApTh-50 and (b) HApTh-450 samples.

a needle-like morphology usually observed on HAp powders obtained by coprecipitation method [22]. Moreover, in TEM images it is easy to observe the formation of a new phase (pyromorphite) with a plate-like morphology (especially in the case of HApTh-450 samples). This behavior suggests that the incorporation of lead in the HApTh matrix stimulates local calcium enrichment.

These images also confirm the hypothesis that the main mechanism of lead immobilization is first of all based on the dissolution of HApTh followed by the precipitation of phases with higher lead content [23].
The Fourier transform infrared spectroscopy provides valuable information about the short-range ordering of materials. In Figure 3 are presented the FTIR spectra of the obtained powders after $\mathrm{Pb}^{2+}$ removal experiments. The interaction between lead (II) and HApTh structure led to some modifications of infrared vibrations of the functional groups. This behavior can be explained by the reaction mechanism which involves the HApTh dissolution in acid environment and HApTh Pb crystallisation [24].

In all the spectra the presence at around $640 \mathrm{~cm}^{-1}$ of $\mathrm{OH}$ vibration peak could be noticed. The broad peaks in the 


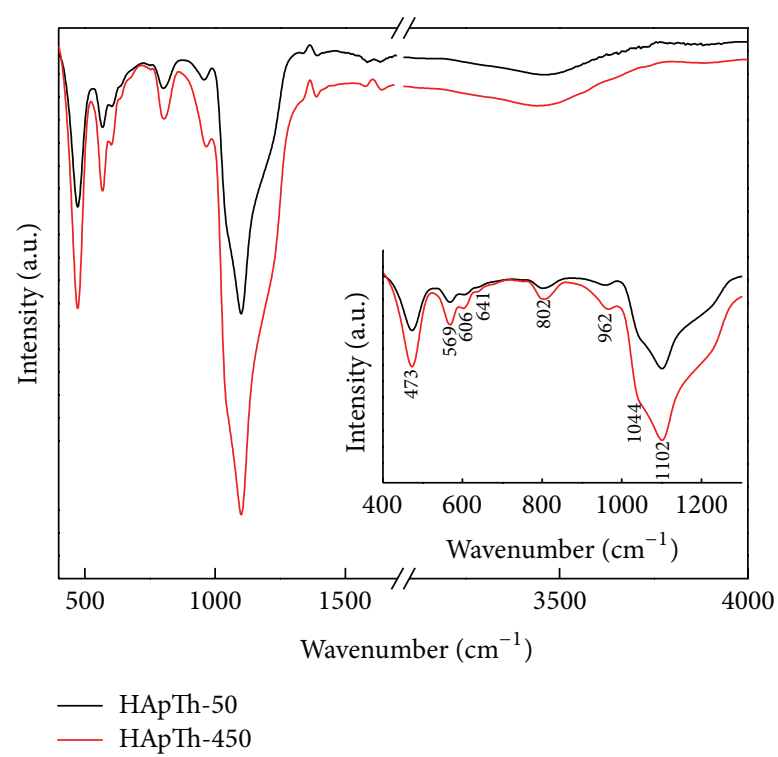

Figure 3: FT-IR spectra of HApTh-50 and HApTh-450 samples.

regions $1600-1700 \mathrm{~cm}^{-1}$ and $3200-3400 \mathrm{~cm}^{-1}$ are attributed to the hydroxyl groups [25-27].

The specific bands of $\left(\mathrm{PO}_{4}{ }^{3-}\right)$ phosphate groups characteristic to hydroxyapatite structure were observed at $568 \mathrm{~cm}^{-1}, \quad 637 \mathrm{~cm}^{-1}, \quad 605 \mathrm{~cm}^{-1}, \quad 964 \mathrm{~cm}^{-1}$, and $1000-$ $1100 \mathrm{~cm}^{-1}[28,29]$. The $964 \mathrm{~cm}^{-1}$ band can be associated to the $v_{1}$ nondegenerated symmetric stretching mode of $\mathrm{P}-\mathrm{O}$. The vibrational bands at $605 \mathrm{~cm}^{-1}$ and $568 \mathrm{~cm}^{-1}$ are attributed to the triply degenerated $v_{4}$ vibration of $\mathrm{O}-\mathrm{P}-\mathrm{O}$ bond, and the band at $472 \mathrm{~cm}^{-1}$ may be attributed to the $v_{2}$ bending of $\mathrm{O}-\mathrm{P}-\mathrm{O}$ bond. Moreover, the weak band observed around $1500 \mathrm{~cm}^{-1}$ could be assigned to the A-type carbonate ion substitutions, whereas the bands at $1422-1456 \mathrm{~cm}^{-1}\left(\nu_{3}\right)$ can be attributed to $\mathrm{B}$-type $\mathrm{CO}_{3}{ }^{2-}$ substitutions [30-32].

Moreover, it is well known that the vibrations bands (stretching and bending) assigned to the $\mathrm{Si}-\mathrm{O}-\mathrm{Si}$ bonds appear in the $1100-900 \mathrm{~cm}^{-1}$ and $550-400 \mathrm{~cm}^{-1}$ spectral regions. In the FTIR spectra (Figure 3 ) it is obvious that the stretching and bending bands of $\mathrm{SiO}_{4}$ groups are overlapping with the band of the $\mathrm{PO}_{4}$ group [30,31, 33-37].

According to Ping et al. [38] the vibration band at $806 \mathrm{~cm}^{-1}$ (HApTh-450 sample) could be attributed to Si-O stretching of dimer silicate chains, indicating the start of silicate polymerization.

The Raman spectra of the HApTh-50 and HApTh-450 powders are reported in Figure 4. The Raman vibrations bands at 959 and $924 \mathrm{~cm}^{-1}$ are attributed to the $v_{1} \mathrm{PO}_{4}$ vibration modes. In HApTh-50 samples, only the $959 \mathrm{~cm}^{-1}$ band appears, whereas the HApTh-450 samples exhibit two bands, one strong at $959 \mathrm{~cm}^{-1}$ and the other band at $924 \mathrm{~cm}^{-1}$. This behavior is caused by the $\mathrm{A}_{\mathrm{g}}-\mathrm{E}_{2 \mathrm{~g}}$ splitting in the hexagonal $C_{6 \mathrm{~h}}$ symmetry $[38,39]$.

For the all samples, the vibrational spectra exhibit a strong molecular character associated with the internal modes of the tetrahedral $\mathrm{PO}_{4}{ }^{3-}$. The $v_{2}$ bands $\left(426 \mathrm{~cm}^{-1}\right.$ and $\left.450 \mathrm{~cm}^{-1}\right)$

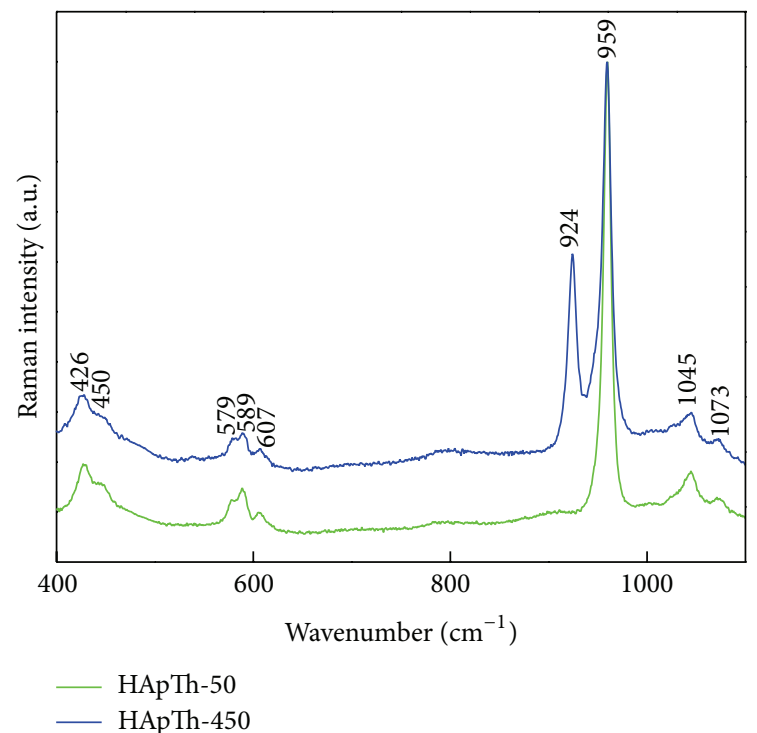

Figure 4: Raman spectra for the HApTh-50 and HApTh-450 samples.

are attributed to the $\mathrm{O}-\mathrm{P}-\mathrm{O}$ bending modes; $v_{3}$ vibration bands $\left(1073 \mathrm{~cm}^{-1}\right.$ and $\left.1045 \mathrm{~cm}^{-1}\right)$ correspond to asymmetric $\mathrm{P}-\mathrm{O}$ stretching and the $v_{4}$ bands $\left(579 \mathrm{~cm}^{-1}, 589 \mathrm{~cm}^{-1}\right.$ and $607 \mathrm{~cm}^{-1}$ ) are attributed mainly to $\mathrm{O}-\mathrm{P}-\mathrm{O}$ bending.

In order to evaluate the impact of the lead concentration in the aqueous solution, absorption experiments were performed. HApTh solutions with concentration varying from 0.1 to $1.5 \mathrm{~g} \cdot \mathrm{L}^{-1}$ at $\mathrm{pH} 5$ were used. The measurements were performed on $500 \mathrm{~mL}$ solution ( $\mathrm{pH}$ 5) with an initial $\mathrm{Pb}^{2+}$ ion concentration of $63 \mathrm{mg} \cdot \mathrm{L}^{-1}$. In Figure 5 the adsorption efficiency of $\mathrm{Pb}^{2+}$ ions as a function of the $\mathrm{Pb}^{2+}$ concentration in the solution is presented. It was observed that the removal efficiency is dependent on the initial $\mathrm{Pb}^{2+}$ concentration. For a lead concentration of $0.2 \mathrm{~g} \cdot \mathrm{L}^{-1}$, the removal efficiency reached 98.6\%, showing that the adsorbent material (HApTh) has a strong affinity to $\mathrm{Pb}^{2+}$ ions. For $\mathrm{Pb}^{2+}$ concentration ranging from $0.4 \mathrm{~g} \cdot \mathrm{L}^{-1}$ to $1.5 \mathrm{~g} \cdot \mathrm{L}^{-1}$, the removal efficiency was around $100 \%$. This behavior could be explained by the fact that the $\mathrm{Pb}^{2+}$ ions were completely removed from the solution.

Figure 5 shows the measured lead concentration in the solution after the reaction with HApTh has taken place. For the studies on the effect of the solution $\mathrm{pH}$, a solution containing $0.9 \mathrm{~g} \cdot \mathrm{L}^{-1}$ of lead was selected (Figure 6). A solution containing $563 \mathrm{mg} \cdot \mathrm{L}^{-1}$ of $\mathrm{Pb}^{2+}$ ions was obtained from $0.9 \mathrm{~g}$ of $\mathrm{Pb}\left(\mathrm{NO}_{3}\right)_{2}$ in $1 \mathrm{~L}$ of distilled water.

A removal efficiency of $100 \%$ was achieved for $\mathrm{pH} 6$. On the other hand, the removal efficiency of $\mathrm{Pb}^{2+}$ ions was $98.5 \%$ at $\mathrm{pH}$ 3. The removal efficiency of $\mathrm{Pb}^{2+}$ ions was $99 \%$ for $\mathrm{pH} 4$. When the $\mathrm{pH}$ value was set to 5 the removal efficiency of $\mathrm{Pb}^{2+}$ ions was $99.5 \%$. The present studies have shown that the removal of $\mathrm{Pb}^{2+}$ ions from aqueous solution by hydroxyapatite/TEOS nanocomposites was greater than $98.6 \%$ at all $\mathrm{pH}$ values of the aqueous solution used for the removal of $\mathrm{Pb}^{2+}$ ions. 


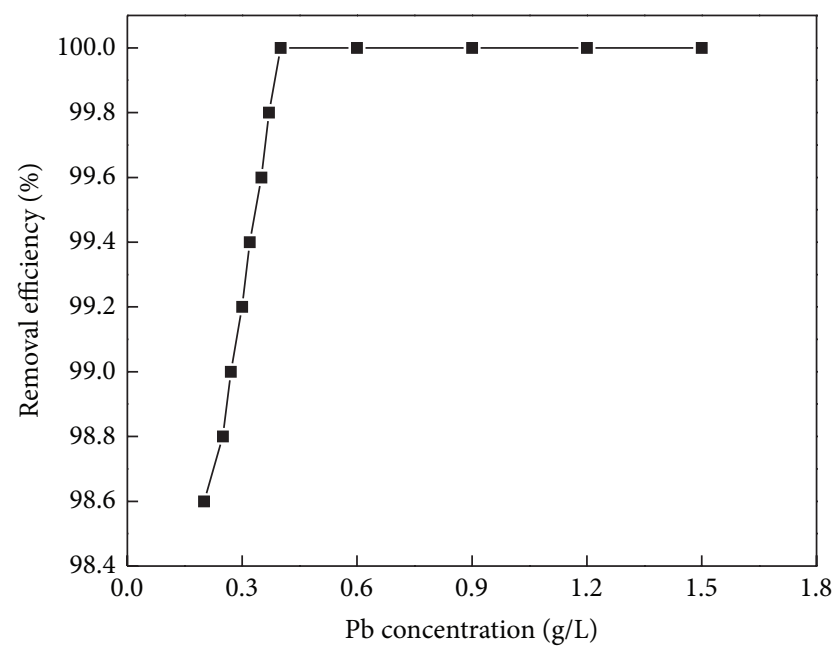

Figure 5: Effect of the $\mathrm{Pb}^{2+}$ concentration on the removal of the $\mathrm{Pb}^{2+}$ ions by HApTh.

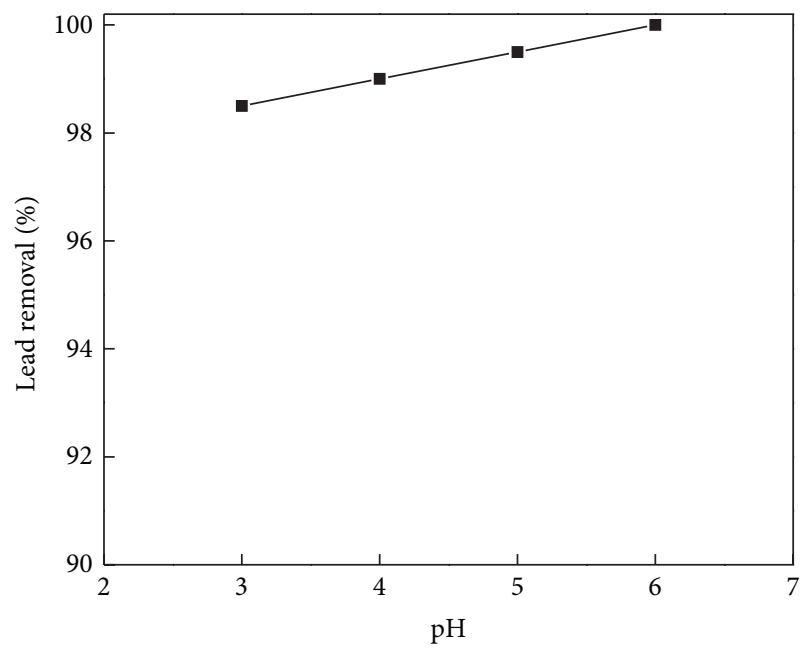

FIGURE 6: Effect of the solution $\mathrm{pH}$ on the removal of $\mathrm{Pb}^{2+}$ ions by HApTh.

According to these results, it can be highlighted the fact that the HApTh can really remove $\mathrm{Pb}^{2+}$ ions from aqueous solutions.

One of the most important parameters which must be considered in the absorption experiments is the $\mathrm{pH}$ of the solutions due to the fact that the $\mathrm{pH}$ of groundwater and surface waters varies between 5 and 7 [40]. The results of our studies have shown that the solid reaction products of aqueous $\mathrm{Pb}^{2+}$ with the HApTh are mainly $\mathrm{pH}$-dependent, this being in good agreement with other results reported in literature [40].

For the assimilation of different metals from aqueous solutions by hydroxyapatite [17, 41-43] different processes have been proposed, such as metal complexation on the HAp surface, apatite dissolution followed by a new metal phase precipitation, and cation exchange. In previous studies [44], it has been shown that the formation of a stable lead apatite such as $\mathrm{Ca}_{(10-x)} \mathrm{Pb}_{x}\left(\mathrm{PO}_{4}\right)_{6}(\mathrm{OH})_{2}$ by ion exchange mechanism where $\mathrm{Pb}^{2+}$ present in the solution replaces $\mathrm{Ca}^{2+}$ ions from the hydroxyapatite lattice is possible. Furthermore, the $\mathrm{Pb}_{(10-x)} \mathrm{Ca}_{x}\left(\mathrm{PO}_{4}\right)_{6}(\mathrm{OH})_{2}$ crystals with higher content of calcium are unstable [45]. Therefore, the HAp should be subject of a permanent process of dissolution and precipitation in order to obtain more stable materials with a higher lead percentage.

\section{Conclusions}

The main goal of this study was to synthesize a new porous nanocomposite material based on tetraethyl orthosilicate (TEOS) coated hydroxyapatite. In this study we investigated the ability of these new materials to remove $\mathrm{Pb}^{2+}$ ions from aqueous solutions with different concentration and $\mathrm{pH}$ values. After HApTh reacted with the solution containing $\mathrm{Pb}^{2+}$ ions, the lead ions were completely removed from the solution and the dissolution of $\mathrm{Ca}_{10}\left(\mathrm{PO}_{4}\right)_{6}(\mathrm{OH})_{2}$ occurred. The HApTh powders exhibited the higher removal efficiency of $\mathrm{Pb}^{2+}$ ions at $\mathrm{pH}$. The TEM studies confirm the hypothesis that the main mechanism of lead immobilization is first of all based on the dissolution of HAp followed by the precipitation of phases with higher lead content. This study showed that the HApTh nanopowders are promising materials for lead ions removal from aqueous solutions with different $\mathrm{pH}$ values, being able to be used in the future for depollution of wastewaters.

\section{Conflict of Interests}

The authors declare that there is no conflict of interests regarding the publication of this paper.

\section{Acknowledgment}

The financial and encouragement support was provided by the Ministry of Educations of Romania under the project IFACEA C2-06.

\section{References}

[1] D. Liao Dexiang, W. Zheng, X. Li et al., "Removal of lead(II) from aqueous solutions using carbonate hydroxyapatite extracted from eggshell waste," Journal of Hazardous Materials, vol. 177, no. 1-3, pp. 126-130, 2010.

[2] S. H. Jang, B. G. Min, Y. G. Jeong, W. S. Lyoo, and S. C. Lee, "Removal of lead ions in aqueous solution by hydroxyapatite/polyurethane composite foams," Journal of Hazardous Materials, vol. 152, no. 3, pp. 1285-1292, 2008.

[3] H. Xu, L. Yang, P. Wang, Y. Liu, and M. Peng, "Kinetic research on the sorption of aqueous lead by synthetic carbonate hydroxyapatite," Journal of Environmental Management, vol. 86, no. 1, pp. 319-328, 2008.

[4] Q. Y. Ma, T. J. Logan, S. J. Traina, and J. A. Ryan, "Effects of NO3-, Cl-, F-, SO42-, and CO32- on Pb2+ immobilization by hydroxyapatite," Environmental Science and Technology, vol. 28, no. 3, pp. 408-418, 1994. 
[5] A. L. Morrison, "An assessment of the effectiveness of lead pollution reduction strategies in North Lake Macquarie, NSW, Australia," The Science of the Total Environment, vol. 303, no. 1-2, pp. 125-138, 2003.

[6] G. B. Freeman, J. A. Dill, J. D. Johnson, P. J. Kurtz, F. Parham, and H. B. Matthews, "Comparative absorption of lead from contaminated soil and lead salts by weanling Fischer 344 rats," Fundamental and Applied Toxicology, vol. 33, no. 1, pp. 109-119, 1996.

[7] A. Günay, E. Arslankaya, and I. Tosun, "Lead removal from aqueous solution by natural and pretreated clinoptilolite: adsorption equilibrium and kinetics," Journal of Hazardous Materials, vol. 146, no. 1-2, pp. 362-371, 2007.

[8] A. Groza, "Review of the processes identified during the polymerization of organic and organosilicon liquid films in atmospheric pressure air corona discharges," Romanian Reports in Physics, vol. 64, no. 4, pp. 1227-1242, 2012.

[9] S. E. Bailey, T. J. Olin, R. M. Bricka, and D. D. Adrian, "A review of potentially low-cost sorbents for heavy metals," Water Research, vol. 33, no. 11, pp. 2469-2479, 1999.

[10] P. Zhang, J. A. Ryan, and J. Yang, "In vitro soil Ph solubility in the presence of hydroxyapatite," Environmental Science and Technology, vol. 32, no. 18, pp. 2763-2768, 1998.

[11] E. S. Bogya, R. Barabás, A. Csavdári, V. Dejeu, and I. Bâldea, "Hydroxyapatite modified with silica used for sorption of copper(II)," Chemical Papers, vol. 63, no. 5, pp. 568-573, 2009.

[12] A. Corami, S. Mignardi, and V. Ferrini, "Cadmium removal from single- and multi-metal $(\mathrm{Cd}+\mathrm{Pb}+\mathrm{Zn}+\mathrm{Cu})$ solutions by sorption on hydroxyapatite," Journal of Colloid and Interface Science, vol. 317, no. 2, pp. 402-408, 2008.

[13] R. Barabás, A. Pop, E. S. Bogya, and V. Dejeu, "Synthesis and properties of intelligent biomaterials. In 4th Edition of the National Symposium of Biomaterials," Biomaterials and Medical-Surgery Applications, vol. 18-20, pp. 1-12, 2007.

[14] M. Czerniczyniec, S. Farías, J. Magallanes, and D. Cicerone, "Arsenic(V) adsorption onto biogenic hydroxyapatite: solution composition effects," Water, Air, and Soil Pollution, vol. 180, no. 1-4, pp. 75-82, 2007.

[15] D. E. Ellis, J. Terra, O. Warschkow et al., "A theoretical and experimental study of lead substitution in calcium hydroxyapatite," Physical Chemistry Chemical Physics, vol. 8, no. 8, pp. 967-976, 2006.

[16] Y. Xu and F. W. Schwartz, "Lead immobilization by hydroxyapatite in aqueous solutions," Journal of Contaminant Hydrology, vol. 15, no. 3, pp. 187-206, 1994.

[17] Q. Y. Ma, S. J. Traina, T. J. Logan, and J. A. Ryan, "In situ lead immobilization by apatite," Environmental Science and Technology, vol. 27, no. 9, pp. 1803-1810, 1993.

[18] J. Liu, Q. Yang, X. S. Zhao, and L. Zhang, "Pore size control of mesoporous silicas from mixtures of sodium silicate and TEOS," Microporous and Mesoporous Materials, vol. 106, no. 1-3, pp. 6267, 2007.

[19] C. S. Ciobanu, E. Andronescu, A. Stoicu et al., "Influence of annealing treatment of nano-hydroxyapatite bioceramics on the vibrational properties," Digest Journal of Nanomaterials and Biostructures, vol. 6, no. 2, pp. 609-624, 2011.

[20] D. Dieterich, E. Grigat, W. Hahn, H. Hespe, and H. G. Schmelzer, "Principles of polyurethane chemistry and special applications," in Polyurethane Handbook: Chemistry, Raw Materials, Processing, Application, Properties, G. Oertel, Ed., pp. 11-31, Hanser, Munich, Germany, 2nd edition, 1994.
[21] S. H. Jang, Y. G. Jeong, B. G. Min, W. S. Lyoo, and S. C. Lee, "Preparation and lead ion removal property of hydroxyapatite/polyacrylamide composite hydrogels," Journal of Hazardous Materials, vol. 159, no. 2-3, pp. 294-299, 2008.

[22] E. Mavropoulos, A. M. Rossi, N. C. C. da Rocha, G. A. Soares, J. C. Moreira, and G. T. Moure, "Dissolution of calcium-deficient hydroxyapatite synthesized at different conditions," Materials Characterization, vol. 50, no. 2-3, pp. 203-207, 2003.

[23] E. Mavropoulos, N. C. C. Rocha, J. C. Moreira, A. M. Rossi, and G. A. Soares, "Characterization of phase evolution during lead immobilization by synthetic hydroxyapatite," Materials Characterization, vol. 53, no. 1, pp. 71-78, 2004.

[24] A. Melinescu, C. Ţârdei, C. M. Simionescu, V. Marinescu, and A. Miclea, "Removal of $\mathrm{Pb}^{2+}$ toxic ions from aqueous solutions on porous hydroxyapatite granules," Romanian Journal of Materials, vol. 43, no. 2, pp. 223-226, 2013.

[25] D. Predoi, R. V. Ghita, F. Ungureanu, C. C. Negrila, R. A. Vatasescu-Balcan, and M. Costache, "Characteristics of hydroxyapatite thin films," Journal of Optoelectronics and Advanced Materials, vol. 9, no. 12, pp. 3827-3831, 2007.

[26] D. Predoi, M. Barsan, E. Andronescu, R. A. Vatasescu-Balcan, and M. Costache, "Hydroxyapatite-iron oxide bioceramic prepared using nano-size powders," Journal of Optoelectronics and Advanced Materials, vol. 9, no. 11, pp. 3609-3613, 2007.

[27] A. Costescu, I. Pasuk, F. Ungureanu et al., "Physico -chemical properties of nano -sized hexagonal hydroxyapatite powder synthesized by sol-gel," Digest Journal of Nanomaterials and Biostructures, vol. 5, no. 4, pp. 989-1000, 2010.

[28] J. Jeanjean, U. Vincent, and M. Fedoroff, "Structural modification of calcium hydroxyapatite induced by sorption of cadmium ions," Journal of Solid State Chemistry, vol. 108, no. 1, pp. 68-72, 1994.

[29] I. Smičiklas, A. Onjia, S. Raičević, D. Janaćković, and M. Mitrić, "Factors influencing the removal of divalent cations by hydroxyapatite," Journal of Hazardous Materials, vol. 152, no. 2, pp. 876$884,2008$.

[30] I. Rehman and W. Bonfield, "Characterization of hydroxyapatite and carbonated apatite by photo acoustic FTIR spectroscopy," Journal of Materials Science: Materials in Medicine, vol. 8, no. 1, pp. 1-4, 1997.

[31] N. Y. Mostafa, H. M. Hassan, and O. H. Abd Elkader, "Preparation and characterization of $\mathrm{Na}^{+}, \mathrm{SiO}_{4}^{4-}$, and $\mathrm{CO}_{3}^{2-} \mathrm{Co}$-substituted hydroxyapatite," Journal of the American Ceramic Society, vol. 94, no. 5, pp. 1584-1590, 2011.

[32] M. Palard, E. Champion, and S. Foucaud, "Synthesis of silicated hydroxyapatite $\mathrm{Ca}_{10}\left(\mathrm{PO}_{4}\right)_{6-x}\left(\mathrm{SiO}_{4}\right)_{x}(\mathrm{OH})_{2-x}$, Journal of Solid State Chemistry, vol. 181, no. 8, pp. 1950-1960, 2008.

[33] A. Bianco, I. Cacciotti, M. Lombardi, and L. Montanaro, "Sisubstituted hydroxyapatite nanopowders: synthesis, thermal stability and sinterability," Materials Research Bulletin, vol. 44, no. 2, pp. 345-354, 2009.

[34] G. Socrates, Infrared and Raman Characteristic Group Frequencies: Tables and Charts, John Wiley \& Sons, New York, NY, USA, 2001.

[35] L. Borum and O. C. Wilson Jr., "Surface modification of hydroxyapatite. Part II. Silica," Biomaterials, vol. 24, no. 21, pp. 3681-3688, 2003.

[36] A. Groza, A. Surmeian, M. Ganciu, R. Medianu, and I. I. Popescu, " $\mathrm{SIO}_{2}$ - Like thin films generation in corona discharges in air at atmospheric pressure: IR spectroscopy and atomic force microscopy investigations," Journal of Optoelectronics and Advanced Materials, vol. 7, no. 4, pp. 2159-2164, 2005. 
[37] A. Groza, A. Surmeian, M. Ganciu, R. Medianu, and I. I. Popescu, "Infrared spectral investigation of organosilicon compounds under corona charge injection in air at atmospheric pressure," Journal of Optoelectronics and Advanced Materials, vol. 7, no. 5, pp. 2545-2548, 2005.

[38] Y. Ping, R. J. Kirkpatrick, P. Brent, P. F. McMillan, and X. Cong, "Structure of calcium silicate hydrate (C-S-H): near-, mid-, and far-infrared spectroscopy," Journal of the American Ceramic Society, vol. 82, no. 3, pp. 742-748, 1999.

[39] G. Bartholomäi and W. E. Klee, "The vibrational spectra of pyromorphite, vanadinite and mimetite," Spectrochimica Acta A: Molecular Spectroscopy, vol. 34, no. 7-8, pp. 831-843, 1978.

[40] A. Hadrich, A. Lautié, and T. Mhiri, "Vibrational study and fluorescence bands in the FT-Raman spectra of $\mathrm{Ca}_{10-x} \mathrm{~Pb}_{x}\left(\mathrm{PO}_{4}\right)_{6}(\mathrm{OH})_{2}$ compounds," Spectrochimica Acta A, vol. 57, no. 8, pp. 1673-1681, 2001.

[41] A. G. Leyva, J. Marrero, P. Smichowski, and D. Cicerone, "Sorption of antimony onto hydroxyapatite," Environmental Science and Technology, vol. 35, no. 18, pp. 3669-3675, 2001.

[42] T. Suzuki, T. Hatsushika, and Y. Hayakawa, "Synthetic hydroxyapatites employed as inorganic cation-exchangers," Journal of the Chemical Society, Faraday Transactions, vol. 77, no. 5, pp. 1059-1062, 1981.

[43] Y. Suzuki and Y. Takeuchi, "Uptake of a few divalent heavy metal ionic species by a fixed bed of hydroxyapatite particles," Journal of Chemical Engineering of Japan, vol. 27, no. 5, pp. 571-576, 1994.

[44] T. Suzuki, K. Ishigaki, and M. Miyake, "Hydroxyapatites as inorganic cation exchangers. Part 3: exchange characteristics of lead ions $\left(\mathrm{Pb}^{2+}\right)$, Journal of the Chemical Society," Journal of the Chemical Society, Faraday Transactions, vol. 80, pp. 3157-3165, 1984.

[45] G. Lusvardi, G. Malavasi, L. Menabue, and M. Saladini, "Removal of cadmium ion by means of synthetic hydroxyapatite," Waste Management, vol. 22, no. 8, pp. 853-857, 2002. 

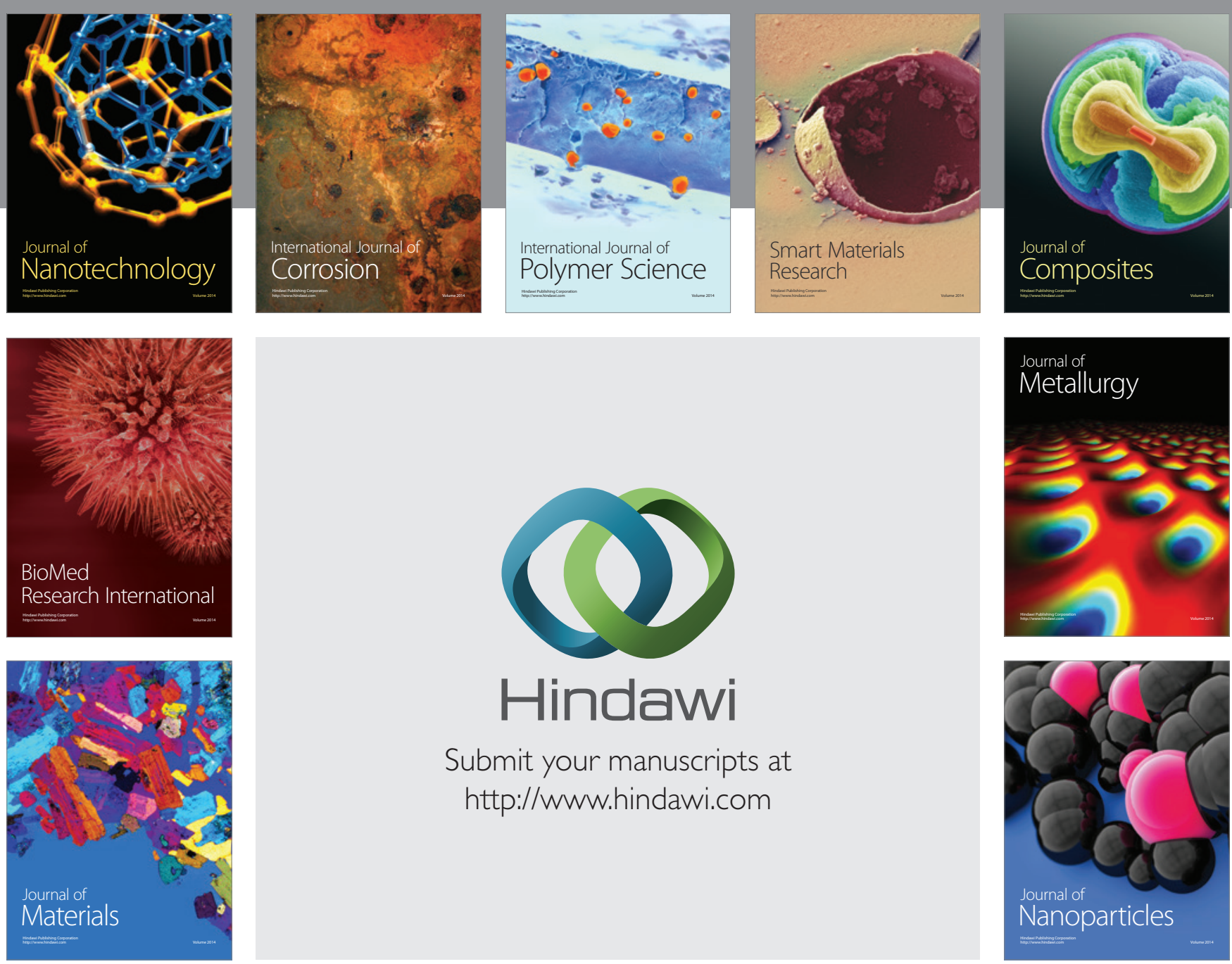

Submit your manuscripts at http://www.hindawi.com
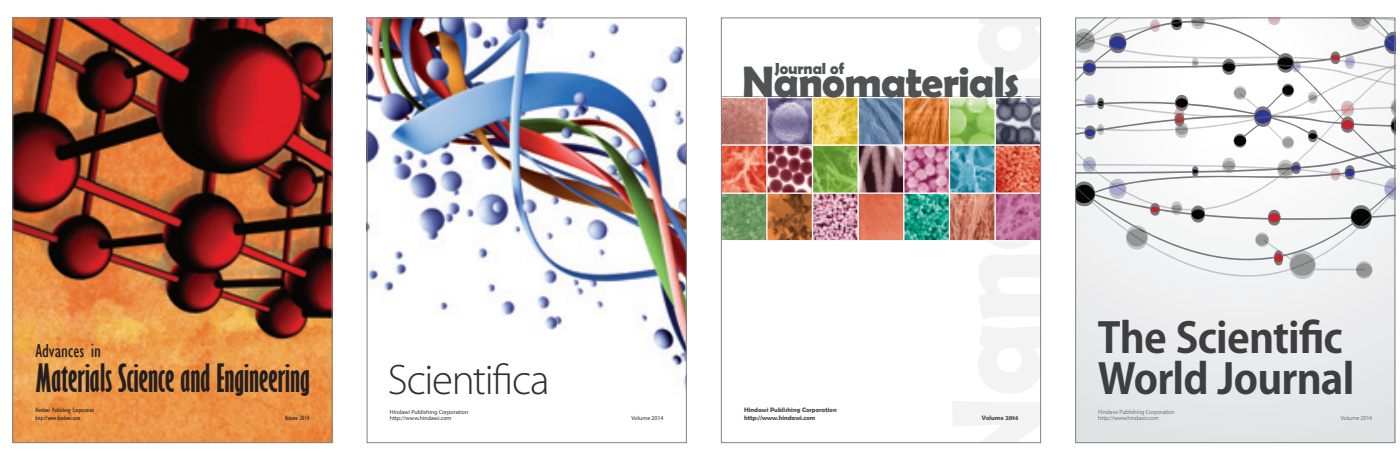

\section{The Scientific World Journal}
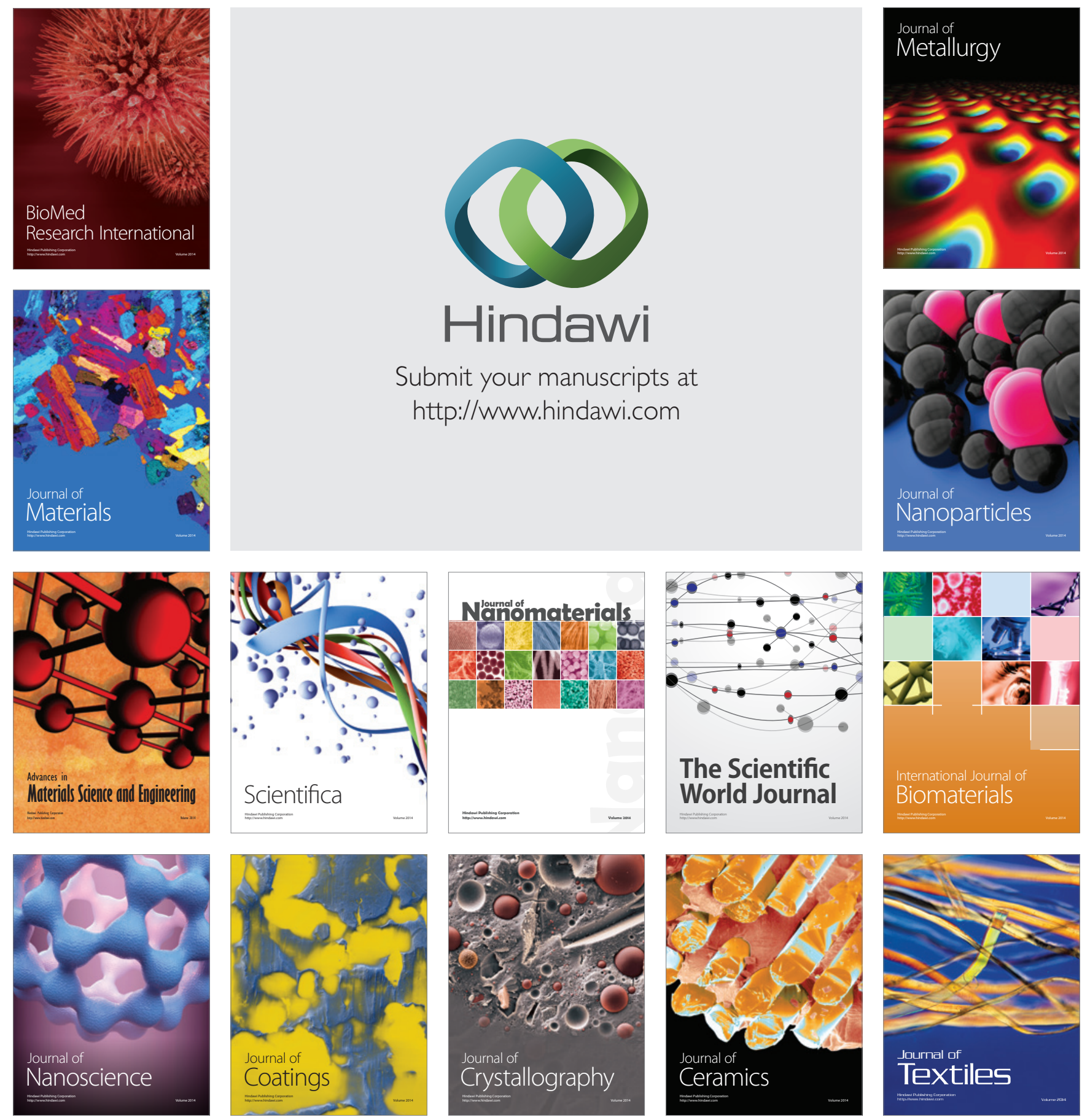